\title{
Business Annual Planning and Controlling in Slovenian Managerial Practice*
}

\author{
Danijel Pučko, Tomasž Čater ${ }^{* *}$
}

Management process is usually segmented into planning, organizing, leading and controlling. The first and the last of these subprocesses are analyzed in the paper from the economic and managerial viewpoint as they occurr in Slovenian enterprise practice. The focus is on empirical research on a tactical level. Business analysis, tactical planning and controlling are the core issues analyzed in the article. The paper builds heavily on presenting empirical findings regarding the empirical systems of tactical enterprise planning and controlling in 50 Slovenian enterprises which are included in the sample. The analytical insights on how much the stated managerial decision-making tools are used in practice and where the main weaknesses are still present are identified. The findings enable the authors to suggest numerous potential improvements in these management systems.

Managementprozesse werden für gewöhnlich in Planung, Organisation, Führung und Controlling untergliedert. Der erste und der letzte dieser Prozesse werden in diesem Beitrag, auf die Praktiken in slowenischen Unternehmen fokussiert und aus ökonomischer und managerialer Sicht analysiert. Dabei liegt das Augenmerk auf empirischer Forschung auf taktischer Ebene. Geschäftsanalyse, taktische Planung und Controlling stehen dabei im Zentrum. Die empirische Basis bilden 50 slowenische Unternehmungen. Der Beitrag zeigt auf, in welchem Maße die genannten Prozesse in der Praxis der untersuchten Unternehmen auftreten und identifiziert Schwächen. Diese Ergebnisse lassen eine Reihe von Vorschlägen hinsichtlich des Verbesserungspotentials zu.

\footnotetext{
* manuscript received: 14.12.2000, accepted: 05.04.2001;

** Danijel Pučko, born 1944, full professor at the University of Ljubljana, Faculty of Economics, Department of Management, Entrepereneurship and Organization. Main research topics: strategic management, business planning and management control. Tomasž Čater, born 1976, assistant at the University of Ljubljana, Faculty of Economics, Department of Management, Entrepreneurship and Organization. Main research topics: strategic management, business economics.
} 


\section{Introduction}

Management quality is a very important variable of the business firm profitability. There are many facets of the management quality; and the quality of the management process (system) is one of them. The planning and controlling systems are important parts of the overall management system. Taking into account the fact that external environments of the business firms in transitional countries became very turbulent and the expectation that in transitional circumstances there will be a certain avoidance of the planning and controlling present in the firms as a "natural" reaction to the previous socialist practice with "too much (formal) planning and controlling", their nowadays role and quality level might be a very relevant research topic.

The purpose of this paper is to present the insights into the empirical tactical planning and controlling systems that are applied by the Slovenian enterprises nowadays as well as to evaluate these systems and to suggest their potential improvements. The empirical research of the tactical planning and controlling systems in enterprises was based on an extensive theoretical study of the relevant literature (Avelini-Holjevac 1998; Belak 1991; Bergant 1993; Camillus 1986; Egger / Winterheller 1994; Kokotec-Novak 1993; Pučko 1981; Pučko 1993; Vollmuth 1997; Weber 1991; Welsch et al. 1988; Ziegenbein 1998) and the survey of a sample of 50 Slovenian enterprises. The questionnaire used in the survey was developed by the authors. Our MBA students carried out the survey while studying the Planning and Controlling subject. Each of them had to choose an enterprise and had to interview the managing director or the chief of the controlling (or adequate) department. The research encompassed the time period from June 1999 to March 2000.

We had $50.0 \%$ manufacturing firms, $30.0 \%$ trading, and $20.0 \%$ firms in the service sector in our sample. A vast majority of the firms was founded before the $1991(89.5 \%) .64 \%$ of the firms were public limited companies, $32 \%$ of the firms were companies with the limited liabilities and $4 \%$ of the firms were state enterprises. Half of the firms in our sample were in the private ownership, $36 \%$ in the mixed and the rest either in the state or other kind of ownership. Mediumsized enterprises prevailed in the sample with the $50 \%$ (they are defined here as enterprises having more than 50 and not more than 500 employees). $44 \%$ of the firms were large and not more than $6 \%$ small. $12.8 \%$ of the firms in the sample operated with a loss in the 1998.

The sample is not a representative one. It is biased in favor of large and medium-sized firms. In spite of this fact we consider the sample as very indicative for the population of medium and large firms in Slovenia. 


\section{Planning and controlling as management functions}

Management process can be divided into at least four subprocesses: planning, organizing, leading and controlling (Možina et al. 1994: 25) ${ }^{1}$. These subprocesses mean that we may deal with four different management subsystems. Two of the stated four subsystems, i. e. the planning and controlling subsystem, will attract our attention here.

Planning as a part of any management process involves defining the future activities and desired business results. The planning could be considered as the first managerial function that initiates the whole management process. It should be based, in the methodological sense, on the findings of business analysis and forecasting of what is more and what less probable to happen in the external environment of an enterprise in the future period. Managers use the results of business analysis and forecasting as inputs into their decision-making. In this way they assure that their planning decisions are rational. They are aware that their behavior should lead to realistic planning objectives and goals. The planned activities must be realistic, too, and well connected with the accomplishment of objectives and goals. The result of the planning process is a plan or a budget. It regularly consists of the whole set of elaborated plans or/and budgets. In their enterprises top managers obviously need a planning system as a wholeness of planning subsystems which assures that all needed partial and financial plans will be formulated in the enterprise in a certain systematic way (Egger / Winterheller 1994: 17). There is really no need to argue that planning is an important management function. It is simply difficult to imagine how one can successfully manage any organization without using planning approaches.

Controlling as a management process (and function) involves a structure and a process of measuring and evaluating what the achievements of the real enterprise are as well as of initiating corrective measures and actions which will assure that the planned objectives, policy and standards are accomplished (Welsch et al. 1988: 15). The control system (structure) is rather permanent in any enterprise. It is focused on the existing business system as it is. Controlling deals with people (Camillus 1986: 11) therefore it deals not just with responsibility centers, accountabilities, effectiveness and efficiency measures and standards, but with behavioral variables, too. The controlling requires information gathering, comparisons of achievements and planning targets, identification of any significant gaps as well as suggesting corrective measures and actions. Controlling is logically a fundament for a new planning cycle.

${ }^{1}$ Different authors use different segmentations of the management process. Avelini-Holjevac prefers to distinguish five management subprocesses (functions): planning, organizing, staffing, leading and controlling (Avelini-Holjevac 1998: 2) 
We should distinguish between controlling as a management function and management control. The latter is a more complex process, which helps managers motivate other members of the organization to implement the organization's strategies and objectives. Management control involves a variety of activities such as planning, coordinating, communicating information, evaluating information, deciding what action to take and influencing people's behavior (Anthony / Govindarajan 1998: 7). Management control is one of the tools used by managers in implementation of the organization's objectives. It is a management system, which can never be reduced to a science. It will always be a science on one hand and an art on the other.

\section{Business analysis, planning and controlling as tools for managerial decision-making}

Management is a decision-making process too. If one deals with the economic aspect of the management decision-making process in a business firm one may talk about the economic control process which covers the business analysis process in its broadest meaning. Business analysis studies business performance of an enterprise with the aim to find out the possibilities for its improvement.

Business analysis may be divided even into two essential parts: the first is a diagnosis, the second a business planning. The wholeness of both means economic control of an enterprise's business operations. The methodological approaches to business analysis consist of numerous analytical methods and techniques which do not allow us to distinguish any methods and techniques which would be separate methods and techniques characteristic just for controlling. In this methodological sense there is no separate controlling phase. Controlling is perceived here as the whole of any business analysis. This interpretation might explain the modern (German) concept of controlling in a clearer way.

Modern controlling is a system of managing the business firm and first of all its business results. It involves planning and informing, analyzing and controlling of all the firm's resources. Its aim is to assure that the firm's objectives will be achieved in a effective and efficient way (Avelini-Holjevac 1998: 4). It is a business system that supports managers in their decision-making. The modern controlling concept is a broader concept compared to the classic control concept. It encompasses business planning and analyzing as well as business informing and coordinating. In the enterprise these tasks are performed by the staff with the support of managers and their decision-making.

Business analysis can be strategic or tactical. Business planning is strategic or tactical. Therefore it is logical to divide modern controlling into strategic and tactical. Operative is the most commonly used term for tactical controlling but it 
is not consistent. According to our interpretation one should understand now that strategic management is not identical with the modern concept of strategic controlling. The first is derived from the organizational (management) aspect, and the second from the economic aspect.

After all these explanations one might be uncertain how to study and analyze the role and the overall quality level of such systems in enterprises. It would certainly be consistent if one chooses to study them at first from the organizational aspect. That would require studying planning and controlling as two separate management subsystems (or functions). Then one could study the process of economic control in enterprises, i.e. business analysis processes (diagnosing and planning) or modern controlling. We chose the first mentioned approach and we explicitly (but not implicitly) disregarded the second in the continuation.

\section{Systems of tactical (annual) planning in Slovenian enterprises: insights and lessons}

\subsection{What is the role of tactical planning in the Slovenian enterprises}

Not all Slovenian enterprises plan strategically ${ }^{2}$. Tactical (annual) plans were elaborated by all enterprises for the year 1999. It is evident that top managers are well aware what the role of a tactical plan in managing the business firm is. Such an attitude is also clearly linked to their assessment of how important annual planning is in the enterprise. They evaluated the importance of annual planning in the enterprise, using a Likert five points scale $(1$ point $=$ not important at all; 5 points $=$ very important). The managing directors (or chiefs of the controlling departments) assigned to the annual planning in average 4.26 points. $50 \%$ of them assigned to this issue the highest possible score (see Table $1)$.

Annual planning is considered important or very important in $82 \%$ of the firms. Only $14 \%$ of the firms find its importance as medium. There are only two firms where the role of annual planning is considered as unimportant. The overall attitude towards annual planning (or budgeting according to many authors) in the Slovenian enterprises seems to be very positive.

${ }^{2}$ The research project Behavior of the Slovenian Enterprises and Financial Institutions in Transition which has been in progress at the Faculty of Economics in Ljubljana since the 1996, showed that $6.4 \%$ of the business firms included in the sample did not plan for more than one year period. 
Table 1: The assessments of the annual planning importance in the Slovenian enterprises

\begin{tabular}{|l|c|c|}
\hline Importance of annual planning & number of the firms & \% of the firms \\
\hline 1. Not important at all & 1 & 2.0 \\
\hline 2. Unimportant & 1 & 2.0 \\
\hline 3. Medium & 7 & 14.0 \\
\hline 4. Important & 16 & 32.0 \\
\hline 5. Very important & 25 & 50.0 \\
\hline Total & 50 & 100.0 \\
\hline
\end{tabular}

Table 2: Benefits of the annual planning according to the managers of the Slovenian enterprises

\begin{tabular}{|l|c|c|}
\hline \multicolumn{1}{|c|}{ Benefits of the annual planning } & $\begin{array}{c}\text { number of } \\
\text { the firms }\end{array}$ & $\begin{array}{c}\text { \% of the } \\
\text { firms }\end{array}$ \\
\hline $\begin{array}{l}\text { 1. Provides a logical and systematic problem- } \\
\text { solving in advance }\end{array}$ & 27 & 54.0 \\
\hline $\begin{array}{l}\text { 2. Enables the avoidance of crisis and ad hoc } \\
\text { problem-solving }\end{array}$ & 17 & 34.0 \\
\hline $\begin{array}{l}\text { 3. Determines a consistent framework which } \\
\text { directs the behavior of all actors in the firm }\end{array}$ & 27 & 54.0 \\
\hline $\begin{array}{l}\text { 4. Makes communication and mutual } \\
\text { understanding more effective }\end{array}$ & 12 & 24.0 \\
\hline $\begin{array}{l}\text { 5. Assures a better motivation for } \\
\text { accomplishment of the enterprise's objectives }\end{array}$ & 18 & 36.0 \\
\hline 6. Enables an effective control system & 33 & 66.0 \\
\hline 7. Annual planning has no special importance & 0 & 0.0 \\
\hline
\end{tabular}

In general, the Slovenian managers perceive annual planning as an indispensable managerial tool because it enables the use of an effective control system. $66 \%$ of the respondents stated this benefit (see Table 2). $54 \%$ of the managers perceive the annual planning as the tool for logical and systematic problem solving in advance. The same percentage of the managers appreciates the annual planning because it determines a consistent framework, which directs the behavior of all agents in the enterprise. One third of the respondents use the annual planning because it motivates effective accomplishments of the enterprise's objectives (36\%) and because it enables them to avoid a crisis as 
well as ad hoc problem solving (34\%). One quarter of the managers $(24 \%)$ believe that the annual planning provides easier communication and mutual understanding within their firms.

The survey results show that the respondents are aware of many benefits of the annual planning system as an effective managerial tool. One may wonder why some managers do not trust its stated advantages. It is apparent that many managers use the annual planning but do not see all its potential benefits. This finding will be additionally confirmed when the next characteristic of the enterprise annual planning practice is identified.

There are many Slovenian enterprises that have no annual plan at the beginning of the calendar year. It could be possible that a business year of some enterprises is not the same as a calendar year and therefore those enterprises elaborate their annual plan later during the calendar year. But this reason does not seem to be very relevant. Figure 1 shows when the firms' annual plans were elaborated and accepted for the year 1999. One can easily see that there are not many firms that would define their annual planning period differently from the calendar year. Less than one half of the firms (44.9\%) had elaborated and approved their annual plan before the calendar 1999-year started (see Figure 1). One quarter of the firms (24.5\%) prepared their annual plan in December, which is usually the most appropriate solution. Another quarter of the firms (24.5\%) had an approved annual plan in January. More than $30 \%$ of the firms waited for their annual plan till February or even later.

Figure 1: The approvals of the annual plans for the year 1999

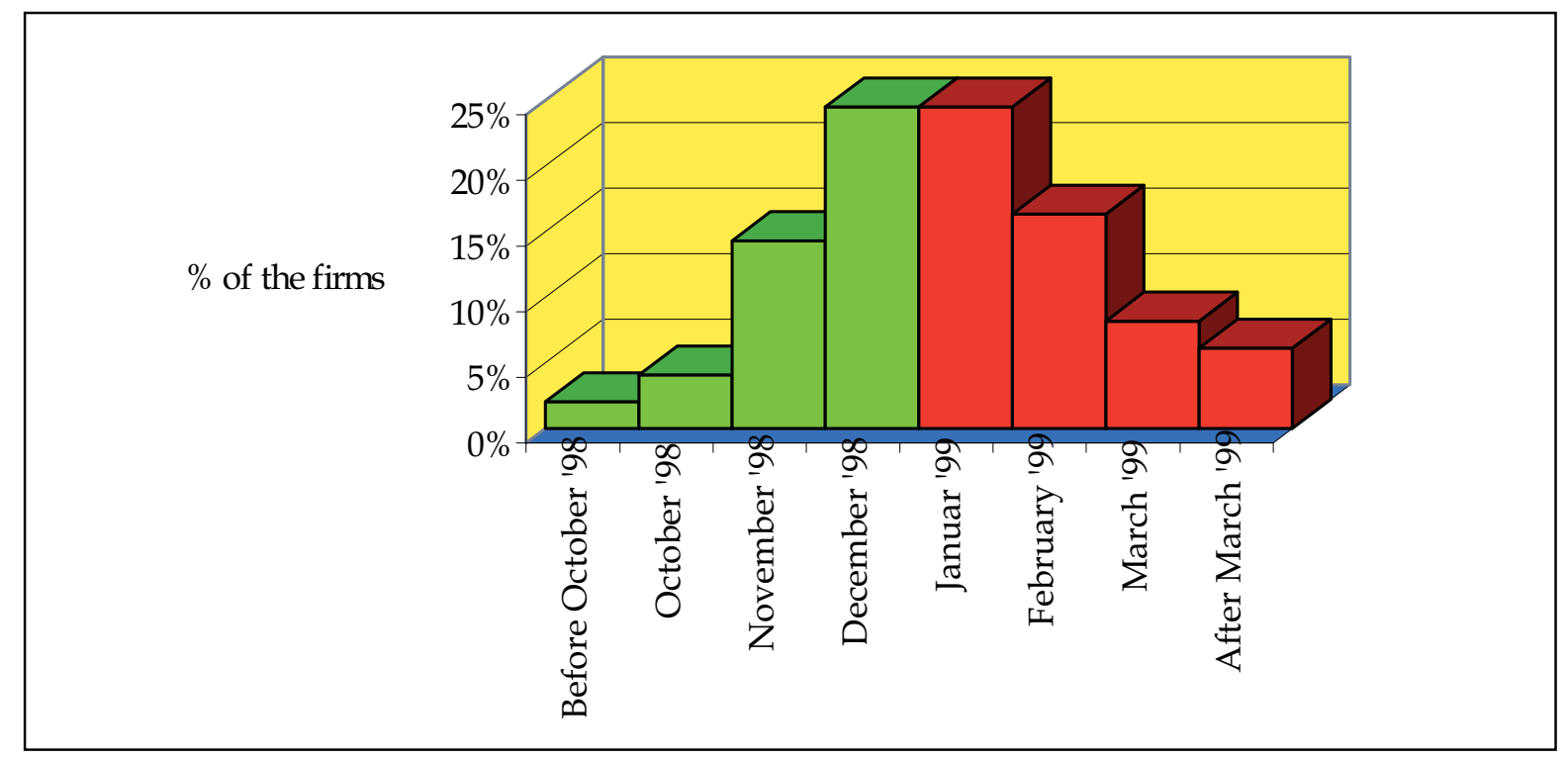

If an enterprise has no annual plan in due time then it can not expect all benefits which stem out of such a plan. The delays in a plan's elaboration and approval might be caused by subjective or objective reasons. Knowing the external environment of the Slovenian enterprises, we believe that such delays are not 
caused in a vast majority of cases because of objective reasons. Therefore one can believe that many Slovenian firms have the possibilities to improve their management.

\subsection{The professional level of the annual planning in the Slovenian enterprises}

The professional level of the annual planning in enterprises can be assessed from many aspects. Our assessment will obviously not be comprehensive because we will try to find out if the enterprises prepare all essential partial and synthetic (financial) budgets (Pučko 1993: 375) within their annual plan, what degree of detailization of their plans is present, and what planning instruments and approaches are used. The respondents' satisfaction with their annual planning system will be shown as well.

\subsubsection{Degree of completeness of the annual planning systems in the Slovenian enterprises}

There are numerous Slovenian enterprises, which do not apply a complex annual planning system (see Figure 2). The majority of enterprises prepare a sales plan (98\%), purchasing plan (82\%), HR plan (78\%), and a plan of salaries (70\%) out of so called partial plans (budgets). All other kinds of partial plans (operating budgets) are prepared in a half or less than a half of all firms. These findings enable us to assess that many firms might significantly improve the quality of their annual planning system by including other operating budgets.

Direct material budgets ( $40 \%$ of firms) and the cost of direct material budgets ( $42 \%$ of firms) are prepared by the minority of enterprises. Direct labor budgets (32\% of firms) and the cost of direct labor budgets (50\%) are also neglected by too many enterprises. It is certainly not a good managerial practice if there is no overhead budget in the firm. Only $26 \%$ of the firms prepare a production overhead budget, not more than $34 \%$ of the firms a sales overhead budget and $42 \%$ of the firms administrative overhead budget. These findings show that the Slovenian enterprises neglect an overhead cost control in the majority of cases. Such a practice must diminish the financial performance of a firm. Few enterprises have a maintenance budget, $R \& D$ budget or a quality assurance budget, which does not contribute to the overall quality of their management.

Most firms use financial budgeting. $82 \%$ of the firms elaborate an income statement budget, $76 \%$ of the firms a financial flows budget and $72 \%$ of the firms a balance sheet budget. Not all firms prepare these three main financial budgets, therefore they should improve the quality of their annual planning. One third of the firms (36\%) plan trade margin. It is a usual practice for the trading companies. A certain weakness was perceived in the field of financial budgeting linked to the financial performance indicators budget. Only two thirds of the 
firms have this kind of a budget. One third of them still disregard the need to elaborate planned financial performance indicators within the annual planning process. If one does not have such indicators, one really does not know how satisfactory the whole set of the elaborated annual plans is. There should be no managing director willing to approve the elaborated set of annual plans if he/she does not have this important information.

\subsubsection{Degree of the budgets' detailization in the Slovenian enterprises}

The majority of the Slovenian enterprises elaborate their sales budget according to product or services groups (78\%). $72 \%$ of the firms elaborate monthly sales quotas. There are less enterprises (56\%) that plan their sales according to sales markets. Sales to customer groups is planned in not more than $38 \%$ of the firms. One quarter of the firms have detailed sales budget according to distribution channels and one fifth according to salesmen. Other ways of the sales budget detailization are almost not present. It is strange that the firms do not plan their sales for their profit centers and other sales units. This fact should be assessed as an essential weakness perceived in sales planning.

Figure 2: What budgets are prepared within the complex annual plan in the Slovenian enterprises

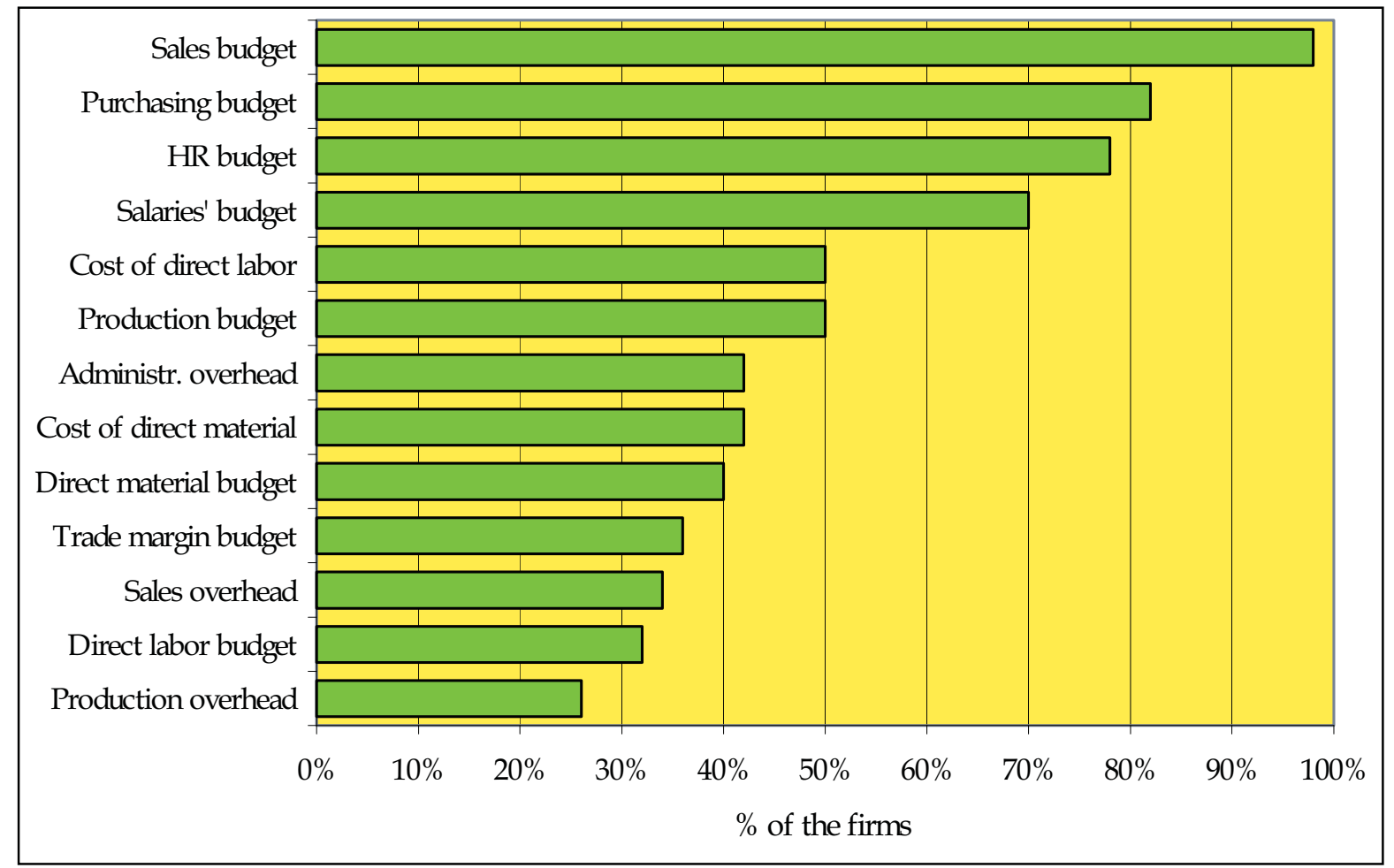

Regarding the production budgets the majority of the Slovenian manufacturing firms prepare these budgets according to groups of products $(80 \%$ of the manufacturing firms). Most of the manufacturing firms also prepare direct material $(80 \%$ of the manufacturing firms) and direct labor $(76 \%$ of the 
manufacturing firms) budgets. On the other hand less than a half of the manufacturing firms plan the production overhead (40\%) and the inventory of finished (44\%) and unfinished (44\%) products. Slovenian manufacturing firms also do not plan the level of their production capacity. All these findings of course suggest how could the systems of the annual production planning in the Slovenian manufacturing firms be improved.

Purchasing budgets are rarely subdivided otherwise than according to kinds of materials and components ( $40 \%$ of the firms) and according to groups of suppliers (24\% of the firms). Only $14 \%$ of the firms prepare a purchasing budget according to purchasing markets. Purchasing cost budget was found in $24 \%$ of the firms. All these findings suggest that there are many possibilities for the upgrading of the planning of purchasing in the Slovenian enterprises.

Direct labor is planned according to the categories of labor (in 30\% of the firms), according to monthly output targets ( $22 \%$ of the firms), according to the responsibility centers (in $24 \%$ of the firms) and according to product groups (in $18 \%$ of the firms). More than $40 \%$ of the firms do not plan direct labor at all. $54 \%$ of the firms have no direct material budget. These findings show potentials for the annual planning improvements in the field of direct cost.

\subsubsection{What planning instruments and techniques are used in the Slovenian enterprises}

Sales forecasts are the assumptions for the annual planning. In a vast majority of the Slovenian enterprises the sales forecasting is rooted in the subjective assessments of the potential sales by the sales manager or marketing manager (in $84 \%$ of the firms). Potential sales are predicted by the controlling department in $8 \%$ of the enterprises. Few firms apply any objective sales forecasting method. It is apparent that the Slovenian entrepreneurial practice does not develop its sales budgets on very sophisticated forecasting approaches.

The planning of those inventories in enterprises which mean the group A according to the $\mathrm{ABC}$ method is carried out on a model (as a general solution for the inventory problem) in not more than $24 \%$ of the firms. $14 \%$ of the firms use an optimal inventory quantity model. $10 \%$ of the firms use some other instruments. The rest of the firms do not use any planning instrument for their inventory planning or do not plan inventories at all.

If we analyze direct material planning practices in the firms that plan direct material at all, then we can find out that material standards are used in direct material planning in $52.6 \%$ of the firms. These standards are based on engineering studies in $38.1 \%$ of the firms, and in $23.8 \%$ of the firms on past material consumption. The rest of the firms use other approaches. $26 \%$ of all firms apply the planning price method in planning direct material cost, $14 \%$ an average price method and only $4 \%$ LIFO method. These findings again show 
that there is much room for improvements in the quality level of annual planning.

Labor standards are defined in the minority of the enterprises. When labor standards in the companies' direct labor planning are used, they are derived by using statistical techniques ( $22 \%$ of the firms), time study ( $20 \%$ of the firms) or subjective assessments (10\% of the firms). It seems that the minority of enterprises uses the appropriate planning instruments for defining their labor standards. The same assessment for the issue of labor rates used in planning is difficult to formulate because we do not have the needed information.

Planning directives are important inputs in a decentralized annual planning process in any firm (Welsch et al. 1988: 129-130). The quality of the planning directives contributes to the overall quality of the planning process in the enterprise. Therefore it is important to assess the quality of this planning instrument in the Slovenian entrepreneurial practice. We found that in $86 \%$ of the firms planning directives were prepared at the very beginning of the annual planning process. Taking into account that there are some small enterprises in our sample, we may assess this practice as good. When we assess the quality of the planning premises our assessment will change. It is apparent that a vast majority of managing directors perceive the planning premises as a document, which should state annual planning objectives and nothing else (see Figure 3). A defined business policy, accepted forecasts, the planning process schedule and a description of the firm's strategy are included in the planning premises of roughly one half of the firms. Other elements do not appear in the premises more frequently. Planning methodological instructions are also rarely included in the premises of the Slovenian enterprises.

\section{Figure 3: What do the planning premises include in the Slovenian enterprises}

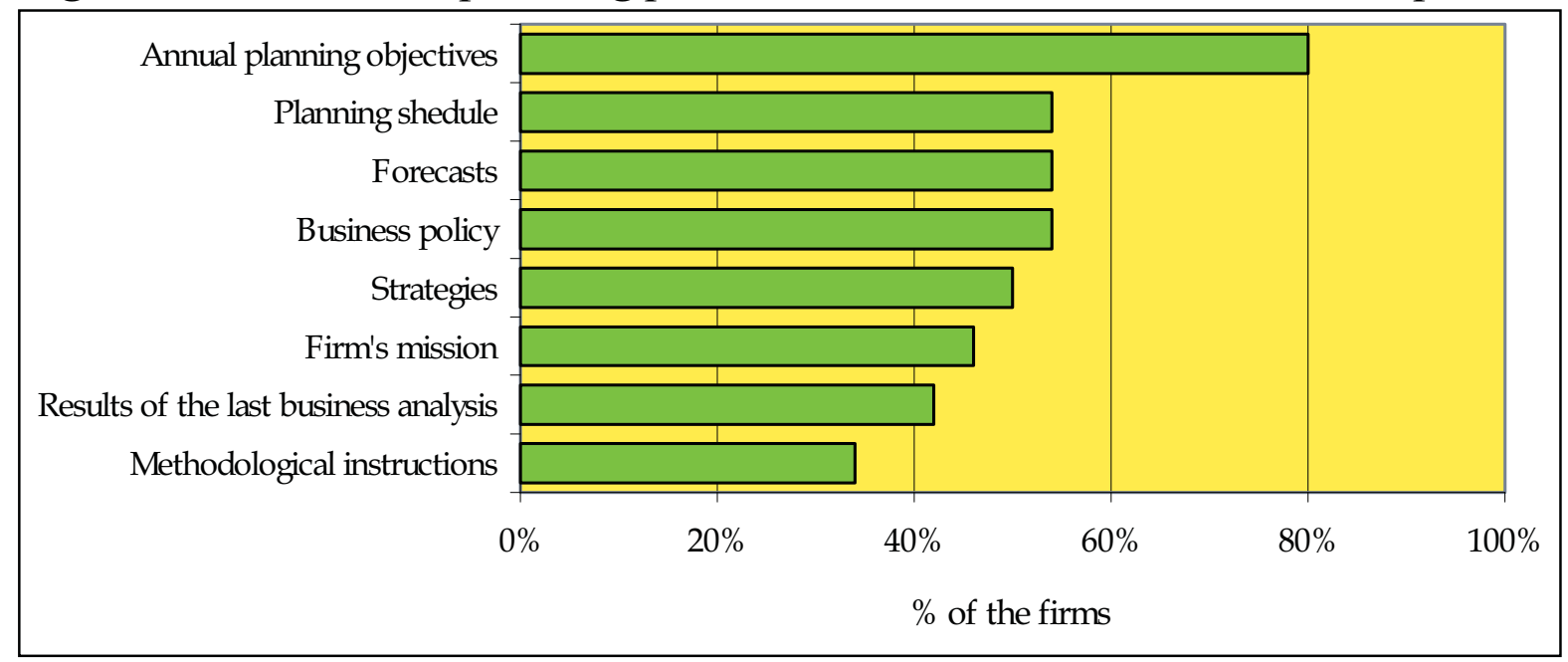

It is a tradition that many Slovenian medium and large enterprises have a written methodology of the annual planning that is prescribed internally in a special document. Such a methodology can be found in $46 \%$ of the enterprises 
in our sample. It usually appears in the form of a planning manual in foreign enterprises (in German Planungshandbuch) (Welsch et al. 1988: 92; Vollmuth 1997: 41). Such a manual can be found in $6 \%$ of the Slovenian enterprises. $44 \%$ of the enterprises do not have any written document, which would prescribe the annual planning methodology in the firm. One can wonder what the quality of the annual planning process in the latter enterprises is.

Table 3: What is included in the annual planning manuals (methodologies) of the Slovenian enterprises

\begin{tabular}{|l|c|c|}
\hline \multicolumn{1}{|c|}{ Items } & $\begin{array}{c}\text { number of the } \\
\text { firms }\end{array}$ & \% of the firms \\
\hline $\begin{array}{l}\text { 1. List of operating and financial } \\
\text { budgets }\end{array}$ & 23 & 46.0 \\
\hline $\begin{array}{l}\text { 2. Obligatory instructions and budget } \\
\text { forms }\end{array}$ & 19 & 38.0 \\
\hline 3. Planning schedule & 20 & 40.0 \\
\hline $\begin{array}{l}\text { 4. Purpose and the role of the annual } \\
\text { planning }\end{array}$ & 17 & 34.0 \\
\hline $\begin{array}{l}\text { 5. Instructions regarding the distribution } \\
\text { of plans }\end{array}$ & 12 & 24.0 \\
\hline $\begin{array}{l}\text { 6. Procedures for the implementation of } \\
\text { the corrective actions if planning gaps } \\
\text { are identified }\end{array}$ & 5 & 10.0 \\
\hline $\begin{array}{l}\text { 7. Procedures for the follow up and } \\
\text { replanning }\end{array}$ & 6 & 12.0 \\
\hline $\begin{array}{l}\text { 8. Planning decision-making } \\
\text { procedures: } \\
\text { a) Line-managers' decisions } \\
\text { b) Staff's decisions } \\
\text { c) Planning board's decisions }\end{array}$ & 6 & 8.0 \\
\hline $\begin{array}{l}\text { 9. Instructions and procedures for } \\
\text { preparing business analysis reports and } \\
\text { their distribution }\end{array}$ & 4 & 2.0 \\
\hline
\end{tabular}

The planning methodologies or manuals in nearly one half of the enterprises (46\%) define operating and financial budgets which should be elaborated (see Table 3), a planning schedule (40\%), and obligatory instructions and forms which must be used in planning (38\%). The manuals describe the purpose and 
the role of the annual planning in one third of the Slovenian firms (34\%). The latter should be included in the planning premises because they are reformulated every year and read by the managers who are supposed to elaborate a budget for his/her responsibility center. The planning manual is a rather permanent document, and it is therefore not consulted carefully by all managers each time their plan is prepared. Other components are not included in the planning methodologies of many Slovenian enterprises (see Table 3).

\subsubsection{Managers' satisfaction with their own annual planning system}

The analysis of the annual planning systems produced a number of suggestions on how these systems might be improved and upgraded. If we confront these suggestions with the (self)assessments given by the managing directors or managers of the controlling departments of the Slovenian firms regarding the quality of their annual planning system a gap could be identified. Our respondents assessed the annual planning system in their enterprise using a five points scale. If they assigned one point to the system, it meant that they considered their system as very bad. If the system was given five points the respondent considered the system as very good. The average grade assigned to the annual planning systems in the Slovenian firms was 3.5 points. Table 4 shows the grading results.

Table 4: Selfassessments of the annual planning systems in the Slovenian enterprises

\begin{tabular}{|l|c|c|}
\hline $\begin{array}{l}\text { Quality level of the annual planning } \\
\text { systems }\end{array}$ & $\begin{array}{c}\text { number of the } \\
\text { firms }\end{array}$ & $\%$ of the firms \\
\hline 1. Very bad & 2 & 4.1 \\
\hline 2. Bad & 4 & 8.2 \\
\hline 3. Medium & 16 & 32.7 \\
\hline 4. Good & 23 & 46.9 \\
\hline 5. Very good & 4 & 8.2 \\
\hline 6. Total & 49 & 100.0 \\
\hline
\end{tabular}

The overall satisfaction of the managing directors or managers of the controlling departments with their annual planning systems seems to be inadequately high. According to their assessments there are not more than $12.3 \%$ of the systems of below the average quality. $55.1 \%$ of the managers assessed their systems as above the average quality. Numerous weaknesses that were found in our analysis show that the Slovenian managers tended to be too optimistic in their assessments. 


\section{Tactical control systems in the Slovenian enterprises}

\subsection{Characteristics of the tactical control systems in the Slovenian enterprises}

There are many kinds of control in enterprises. A well-known classification divides control in feedforward and feedback control. Feedforward control forecasts the appearance of gaps in the implementation of plans and enables their creation. It is connected with a strategic control. Feedback control is a twingle brother of the tactical planning because it identifies gaps between achievements and planning targets, evaluates them and formulates measures and actions for their withdrawal (Pučko 1993: 329). Tactical control is usually a feedback control of the firm's business operations. Here, the standards are defined by the firm's annual plan. They represent planning targets which are the basis for the identification of planning gaps.

Most Slovenian enterprises use a feedback control, which was expected. $90 \%$ of the firms practice a feedback control while not more than a quarter of them (24\%) a feedforward control. A more detailed analysis shows that three quarters of the firms (76\%) use periodic control. Two thirds of the firms (64\%) really apply a feedback control on the basis of their annual plans. More differences among the Slovenian firms are evident in other characteristics of their tactical control systems (see Table 5).

Only $42 \%$ of the firms practice timely control reports. The requirement that the control system should be in the accordance with the responsibility centers is respected in not more than $36 \%$ of the firms. It is well known that a manager should be responsible only for those variables, which can be controlled by $\mathrm{him} / \mathrm{her}$. This rule is not taken into account in the majority of the Slovenian firms $(76 \%)$. Table 5 clearly shows that the majority of enterprises have not built important elements of the effective control into their systems. Therefore these systems should be radically improved.

Sales control focuses on the sales quantity (used in $76 \%$ of the firms) and the sales value (88\%). All other sales control aspects are disregarded in the majority of the firms. Trading companies control trading margin. Sales quotas are controlled in only $22 \%$ of the firms. The same percentage of the firms control promotion expenditures. Distribution cost is controlled in not more than $16 \%$ of the firms. These findings suggest the conclusion that the practical sales control systems are not very sophisticated in the Slovenian entrepreneurial practice.

The systems of production control in the Slovenian manufacturing firms can be assessed with a higher grade than the systems of sales control in the Slovenian enterprises. This judgement can be supported with the following facts: (a) $80 \%$ of the Slovenian manufacturing firms identify the gaps between actual and planned production quantities, (b) $72 \%$ of the Slovenian manufacturing firms control the quality of their products, (c) $64 \%$ of the Slovenian manufacturing 
firms control the consumption of the direct material and the cost of the direct material. Furthermore, $64 \%$ of the Slovenian manufacturing firms control the inventory of finished products, while only $56 \%$ of the Slovenian manufacturing firms control the inventory of unfinished products. It is also quite unsatisfying that only $36 \%$ of the manufacturing firms control the production overhead.

Table 5: Main characteristics of the tactical control systems in the Slovenian enterprises

\begin{tabular}{|l|c|c|}
\hline \multicolumn{1}{|c|}{ Characteristics } & $\begin{array}{c}\text { number of the } \\
\text { firms }\end{array}$ & \% of the firms \\
\hline 1. Control is based on a periodic reports & 38 & 76.0 \\
\hline $\begin{array}{l}\text { 2. Control is based on the identification of } \\
\text { gaps where the annual plan is a standard }\end{array}$ & 32 & 64.0 \\
\hline 3. Control reports are timely & 21 & 42.0 \\
\hline $\begin{array}{l}\text { 4. Control is in the accordance with the } \\
\text { responsibility centers }\end{array}$ & 18 & 36.0 \\
\hline $\begin{array}{l}\text { 5. Controllable variables are defined in } \\
\text { responsibility centers }\end{array}$ & 12 & 24.0 \\
\hline $\begin{array}{l}\text { 6. The best measures are regularly chosen for } \\
\text { correcting gaps }\end{array}$ & 11 & 22.0 \\
\hline 7. Sporadic control reports are used & 7 & 14.0 \\
\hline $\begin{array}{l}\text { 8. Alternative measures for correcting gaps } \\
\text { are developed }\end{array}$ & 6 & 12.0 \\
\hline $\begin{array}{l}\text { 9. Corrective measures are being followed- } \\
\text { up }\end{array}$ & 6 & 12.0 \\
\hline $\begin{array}{l}\text { 10. Replanning is initiated on the basis of a } \\
\text { feedforward control }\end{array}$ & 5 & 10.0 \\
\hline $\begin{array}{l}\text { 11. Control is implemented mostly by } \\
\text { personal control }\end{array}$ & 5 & 10.0 \\
\hline 12. Computer control model is used & 1 & 2.0 \\
\hline
\end{tabular}

The minority of the enterprises control direct labor cost. This control is based on identifying variances between actual direct labor hours and the planned ones in responsibility centers in $22 \%$ of the firms. $12 \%$ of the firms identify these variances using the flexible direct labor cost budget and $6 \%$ of the firms analyze the variances taking the changes in average hourly wages into account too. It seems that the firms do not pay much attention to the direct labor cost in their operations. 
Overhead cost is not a frequent control object in the Slovenian enterprises. Only $22 \%$ of the firms carry out an overhead cost control. Sales (distribution) overhead and administrative overhead cost are controlled in not more than $10 \%$ of the firms. Do managers really believe that these cost items are so unimportant in the firms that they might be easily disregarded?

If the quality of the control system depends significantly on the criteria which are used for the identification of critical variances, then one must mention the findings that $88 \%$ of the Slovenian firms use the criteria based on their experience (historically or statistically derived). Engineering approaches or $\mathrm{ABC}$ method are used in few enterprises.

\subsection{Main weaknesses of the control reports in the Slovenian enterprises}

Control reports determine the quality level of the control systems too. Their characteristics can improve or diminish the general effectiveness of the enterprise's control system (Vollmuth 1997: 66-67). Therefore, let us look at this issue! Figure 4 shows the weakness of the control reports as assessed by the Slovenian managers.

Figure 4: The most frequent weaknesses incorporated in the control reports of the Slovenian enterprises

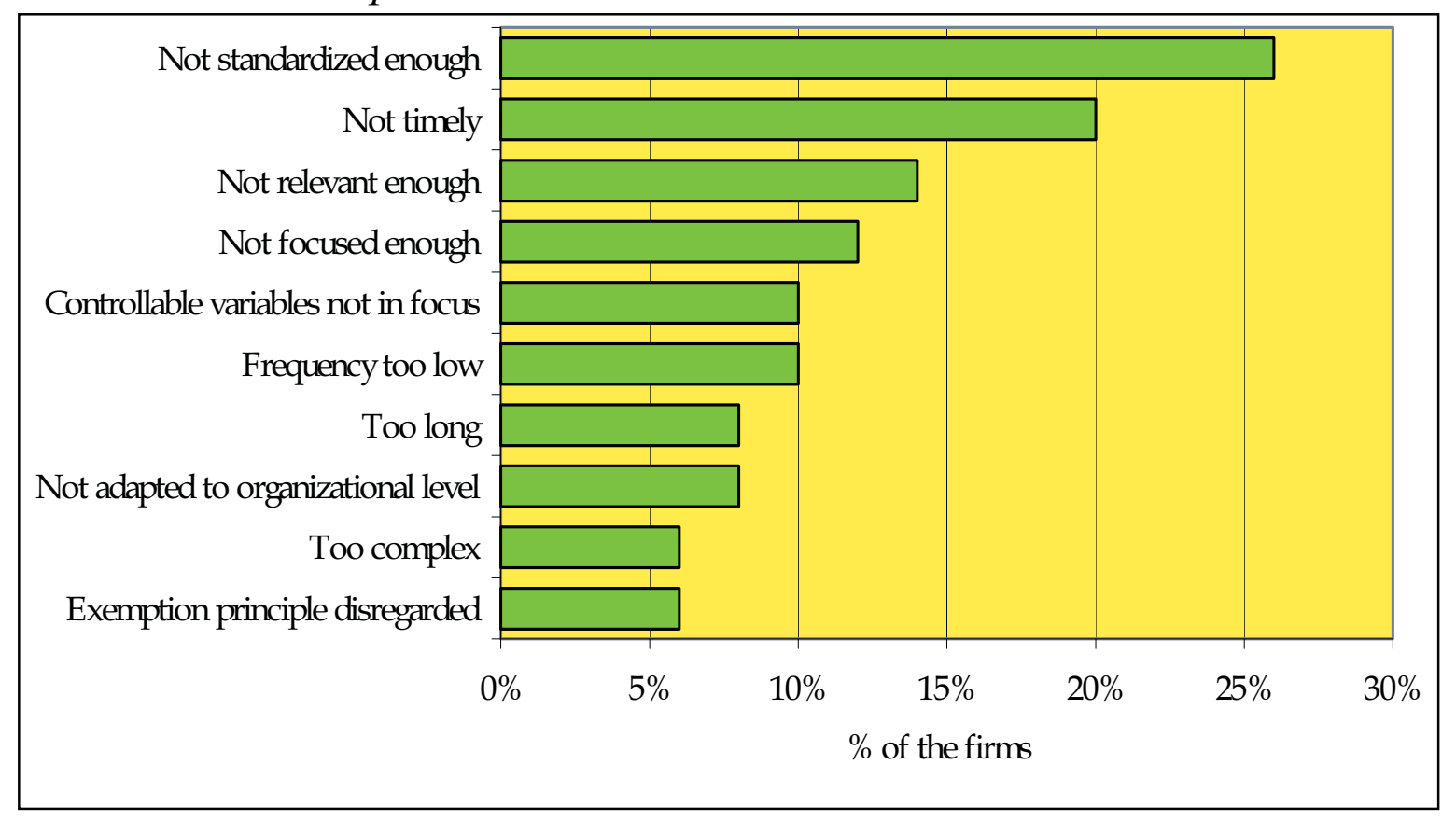

Figure 4 proves that the managers are quite satisfied with their control reports. The percentage shares of those who indicated different weaknesses of the control reports in his/her enterprise are relatively low. On the other hand Figure 4 shows that the control reports could be improved especially regarding their standardization, timeliness, focus on essential items, relevancy, frequency and concentration on controllable variables. 


\subsection{Main behavioral problems in control processes}

Control is a managerial function, which deals with people. Therefore the quality of the control depends on behavioral variables, too. By assessing tactical control systems in enterprises one may not disregard behavioral problems which might be caused by these systems.

Table 6: The most frequent behavioral control problems in the Slovenian enterprises

\begin{tabular}{|l|c|c|}
\hline \multicolumn{1}{|c|}{ Type of problem } & $\begin{array}{c}\text { number of the } \\
\text { firms }\end{array}$ & \% of the firms \\
\hline $\begin{array}{l}\text { 1. Subordinates do not assess variances and } \\
\text { do not look for their causes }\end{array}$ & 24 & 48.0 \\
\hline $\begin{array}{l}\text { 2. Subordinates are not motivated properly } \\
\text { for the accomplishment of planning } \\
\text { objectives }\end{array}$ & 12 & 24.0 \\
\hline $\begin{array}{l}\text { 3. Superiors are not ready to accept the } \\
\text { proposed measures by their subordinates }\end{array}$ & 8 & 16.0 \\
\hline $\begin{array}{l}\text { 4. Subordinates are afraid because of the } \\
\text { control and therefore show too low level of } \\
\text { initiatives and creativity }\end{array}$ & 7 & 14.0 \\
\hline $\begin{array}{l}\text { 5. Subordinates are afraid because of the } \\
\text { control and are therefore too careful and } \\
\text { defensive }\end{array}$ & 7 & 14.0 \\
\hline $\begin{array}{l}\text { 6. Subordinates do not participate in } \\
\text { planning, which causes problems in control }\end{array}$ & 7 & 14.0 \\
\hline $\begin{array}{l}\text { 7. Conflicts which stem out of unclearly } \\
\text { defined accountabilities of line managers } \\
\text { and staff }\end{array}$ & 7 & 14.0 \\
\hline $\begin{array}{l}\text { 8. Superiors use control for determining } \\
\text { who is responsible and guilty }\end{array}$ & 2 & 4.0 \\
\hline $\begin{array}{l}\text { 9. Too low level of control that is not } \\
\text { effective enough }\end{array}$ & 2 & 4.0 \\
\hline $\begin{array}{l}\text { 10. Co-employees are overburdened with } \\
\text { other routine tasks }\end{array}$ & 1 & 2.0 \\
\hline
\end{tabular}

The empirical research was focused on the behavioral aspects of control systems in the Slovenian enterprises, too. The survey results show that the most frequent and the most important behavioral problem linked to the control 
systems is a too low level of selfcontrol carried out by subordinates in the Slovenian enterprises. $48 \%$ of the respondents assessed that their subordinates do not evaluate variances and do not look for their causes, although the superiors would like them to do it. All other perceived behavioral control problems are shown in Table 6.

\subsection{Satisfaction with the control systems in the Slovenian enterprises}

The Slovenian managing directors or chiefs of the controlling departments were asked how satisfied with their enterprises' control system they were. Their responses show that they are much less satisfied with their tactical control systems as with their tactical planning systems (see Figure 5). There were only $37 \%$ of the respondents whose satisfaction with the control system was above the average level. One third of the respondents (35\%) assessed their control system as good and $51 \%$ as medium. These two types of assessments are dominant. They are not in accordance with the respondents' satisfaction's level with their annual planning systems, which is not very logical.

Figure 5: Comparison of the Slovenian managers' satisfaction with the tactical planning and control system

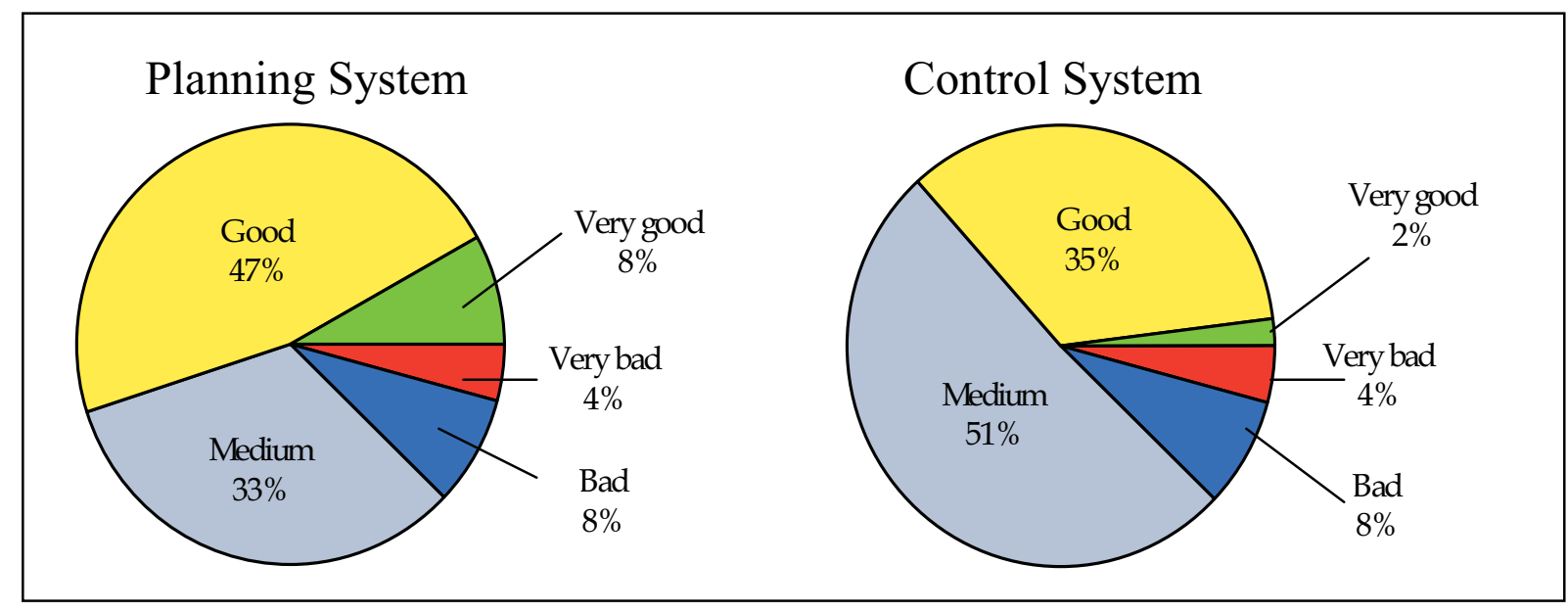

Our analytical findings linked to the quality of the control systems in the Slovenian enterprises do not support the conclusion that these systems would be radically worse compared to the tactical planning systems. On the contrary, the findings stimulate us to suggest that both systems might be improved in numerous components in many firms. One possible explanation on why the respondents assessed both systems differently could be in the fact that the respondents did not pay attention to the theoretical learning maintaining that the feedback control is a twin brother of the tactical planning system. If a good planning system is not used, one should not expect a good control system. We already argued in the subchapter 4.2.4 that the Slovenian managers are oversatisfied with the tactical planning systems in their enterprises. 


\section{Conclusion}

The results of the empirical research results enable us to summarize the main findings regarding the role and the quality of the tactical planning and control systems in the Slovenian entrepreneurial sector in the following ways:

1. The thesis that the tactical planning is neglected in the Slovenian enterprises is not valid. The top managers are well aware of the role of the annual planning. Therefore they apply the annual planning, but their planning systems are not without weaknesses. It seems that the managing directors are even too satisfied with their systems.

2. More than one half of the enterprises will have to change their practice and prepare and approve their annual plan before the planning year starts.

3. There are many enterprises, which do not prepare all needed operating and financial annual budgets. Direct material and direct labor budgets as well as direct material and direct labor cost budgets are neglected in the majority of enterprises. The overhead cost is planned in the minority of the firms as well as maintenance and $\mathrm{R} \& \mathrm{D}$.

4. The vast majority of enterprises prepare their annual financial budgets. There is still about one quarter of them that neglect their preparation. One third of them consider that they do not need a budget of financial performance indicators.

5. The following research findings suggest how the annual planning systems in the Slovenian enterprises could be improved:

a) Firms should plan their sales according to their sales market, customer groups, distribution channels and profit centers, too.

b) Manufacturing firms should improve their production planning systems by planning their production overhead, production capacity and inventory of finished and unfinished products.

c) Firms should regularly plan their purchasing according to kinds of materials and components, groups of suppliers and purchasing markets, which is a rather neglected practice at the moment. A monthly purchasing dynamics of the annual purchasing plan is usually not elaborated too.

d) Sales forecasting could be upgraded by substituting managerial judgmental methods with more sophisticated forecasting methods.

e) Inventory planning should be built on the well known models.

f) The quality of planning premises might be significantly improved by including many more important items in the premises. 
g) The effectiveness of the annual planning processes and their quality level would be upgraded if the enterprises developed a comprehensive planning manual.

6. The vast majority of the Slovenian enterprises have a tactical control system, which enables them to practice the periodic control by identifying variances between actual achievements and planning targets. In spite of this the control quality level seems to be questionable in many enterprises, which is confirmed by their critical assessments given by the managers. Our analytical assessments of these systems suggest that they could be improved in many ways. The most important ones are the following:

a) The firms should prepare control reports in due time.

b) The control system must be in accordance with the responsibility centers in the enterprise.

c) Managers must define controllable variables for each responsibility center.

d) Sales control should not be built just on sales quantity and sales value for the whole enterprise.

e) Overhead cost control should not be a neglected control subsystem anymore.

f) The control of direct labor and cost of direct labor could contribute to a better financial performance of many firms.

g) Control reports could be improved in many ways. Figure 4 indicate them well.

7. The identified control behavioral problems suggest possible directions of the improvements of the control systems. The level of selfcontrol should be upgraded. Weaknesses in the motivational systems, which diminish the employees' endeavors to accomplish the planning objectives and goals, should be abolished. The mutual cooperation of the subordinates and their superiors in the field of control processes might be improved. Any reduction in control behavior problems might improve the quality level of the enterprise's control system.

In spite of the fact that our research findings are not comprehensive they indicate how the important managerial tools in the Slovenian entrepreneurial practice might be upgraded in the future. Here we discussed managerial tools in the field of annual planning and controlling. Our discussion was constrained to a rather broad but still very limited field of managerial decision-making. Those managers who are willing can quite clearly perceive on the basis of our findings and suggestions, what their future tasks in developing the relevant tools will be. In the implementation of these tasks they will certainly include their chiefs of the controlling departments. 
Nearly one half of the enterprises in our sample have a controlling department ( $47.8 \%$ of the firms). Only $16 \%$ of the firms have an independent controlling unit that is subordinated directly to the enterprise's managing director. Otherwise these units are subunits within other departments in the organizational hierarchy in the enterprise. They deal mainly with business analysis (in $54 \%$ of the firms), annual planning (in 56\% of the firms), strategic planning (in $22 \%$ of the firms), and control (in $42 \%$ of the firms). Controlling departments as staff departments can contribute significantly to the improvements of the relevant decision-making systems in enterprises. They will be successful in performing these tasks if managing directors fully support their endeavors.

\section{References}

Anthony, N. R. / Govindarajan, V. (1998): Management Control Systems, New Delhi: Tata McGraw-Hill Publishing Company Limited.

Avelini-Holjevac, I. (1998): Kontroling, Opatija: Hotelijerski fakultet.

Belak, J. (1991): Podjetniško planiranje kot orodje vodenja politike podjetja, Maribor: Obzorja.

Bergant, Ž. (1993): Nekateri vidiki budžetiranja v podjetju", in: ib revija, No. 8-9-10, pp 8893.

Camillus, J. (1986): Strategic Planning and Control, Toronto: Lexington Books.

Egger, A. / Winterheller, M. (1994): Kurzfristige Unternemensplanung, Wien: Linde Verlag.

Kokotec-Novak, M. (1993): "Budžetiranje v podjetju in razvitost računovodskih funkcij", in: ib revija, No. 8-9-10, pp 82-87.

Možina, S. et al. (1994): Management, Radovljica: Didakta.

Pučko, D. (1993): Planiranje v podjetjih, Ljubljana: Univerza v Ljubljani, Ekonomska fakulteta.

Pučko, D. (ed.) (1981): Problemi planiranja v organizacijah združenega dela, Maribor: Obzorja.

Vollmuth, J. H. (1997): Führungsinstrument Controlling, Planegg: Haufe.

Weber, J. (1991): Einführung in das Controlling, I. part, Stuttgart: Poeschel.

Welsch, A. G. et al. (1988): Budgeting, Englewood Cliffs: Prentice Hall.

Ziegenbein, K. (1998): Controlling, Ludwigshafen: Kiehl Verlag GmbH. 